\title{
Intestinal Disaccharidase Activity and Uptake of Glucose from Sucrose
}

\author{
Kia Halschou Hansen, Klaus Bukhave and Jens Rikardt Andersen
}

Additional information is available at the end of the chapter

http://dx.doi.org/10.5772/53099

\section{Introduction}

Postprandial hyperglycemia is now established as an independent risk factor for the development of at least macro vascular complications in diabetes mellitus (1), as it is a widely accepted experience that it is more difficult to normalize postprandial blood glucose than the fasting concentrations. Furthermore, it is well known that impaired glucose tolerance (IGT) is related to increased cardiovascular morbidity and mortality (2) and that postprandial hyperglycemia plays a central role in progression from IGT to type 2 diabetes (3). It is possible to delay the appearance of type 2 diabetes and cardiovascular diseases in IGT patients by good glycemic control (4-8). The glycemic load as well as peak concentrations of glucose in the blood depend on many factors including gastric emptying, the nature of ingested food, intraluminal glucose concentration, and enzymatic activity in the brush border. On top of this several gut hormones play a role as well as the ability of the liver to reduce endogenous glucose production, being a special problem in patients with type 2 diabetes. This phenomenon increases the importance of reducing postprandial glucose uptake in type 2 diabetics. In addition, it seems possible to modify the insulin secretion after meals by addition of arabinose to the ingested sucrose (9). Sucrose contains equal amounts of glucose and fructose molecules. The absorption and metabolism of the two molecules is different. The absorbed glucose is utilized in an insulin dependent manner primarily in the peripheral tissues. Fructose is utilized in the liver in the glycolytic pathway with products like glucose, glycogen, lactate and pyruvate. Fructose is more lipogenic than glucose, an effect that might contribute to the development of cardiovascular diseases (CVD), insulin resistance and type 2 diabetes (10). Fructose does not stimulate insulin secretion as glucose why a modest intake of fructose is recomended in diabetes and heart patients due to the lipogenicity $(10 ; 11)$. Recently, a metaanalysis stated that fructose intake at a level of $\leq 36 \mathrm{~g} / \mathrm{d}$, which is equivalent to daily intake of fruit, could have beneficial effects by decreasing endogenous glucose production and increasing glycogen synthesis, and 
thereby improve glycaemic control. This benefit is seen without the adverse cardiometabolic effects reported when fructose is ingested in high doses or as excess energy (12).

\section{Disaccharidase activity in vitro}

The digestive enzymes, $\alpha$-amylase and $\alpha$-glucosidase are the key enzymes responsible for the digestion of carbohydrates to glucose. In search for modulators and/or inhibitors of disaccharidases various in vitro models for determination have been described in the literature. These represent quick and cheap screening procedures and include among others intestinal mucosa homogenates $(13 ; 14)$, intestinal brush border preparations (15) from different experimental animals, and homogenates of human intestinal cell line Caco-2 (9). The Caco-2 cells were originally derived from a human colon adenocarcinoma. In culture they proliferate and differentiate to cells resembling mature jejunocytes with high levels of brush-border enzyme activity including alkaline phosphatase, amino-peptidase, and sucrase-isomaltase (16). Although the Caco-2 cells are derived from colonic cells they represent human tissue and are thereby superior to animal tissue in relation to human studies. For kinetic studies on disaccharidase activity an in vitro model with homogenates of Caco-2 cells was established. Caco-2 cells from passage number 38 and 39 were seeded onto polycarbonate membranes (Fisher Scientific, Transwell ${ }^{\circledR}$ membrane, $75 \mathrm{~mm}$ ) and cultured at $37^{\circ} \mathrm{C}$ and $5 / 95 \% \mathrm{CO}_{2} /$ air. At day 20-22, when the transepithelial electrical resistance (TEER) has reached a steady state level of 3-400 $\Omega^{*} \mathrm{~cm}^{2}$, the Caco-2 cells were rinsed with phosphate buffered saline, scraped off the membranes, and homogenized by sonication. Homogenates

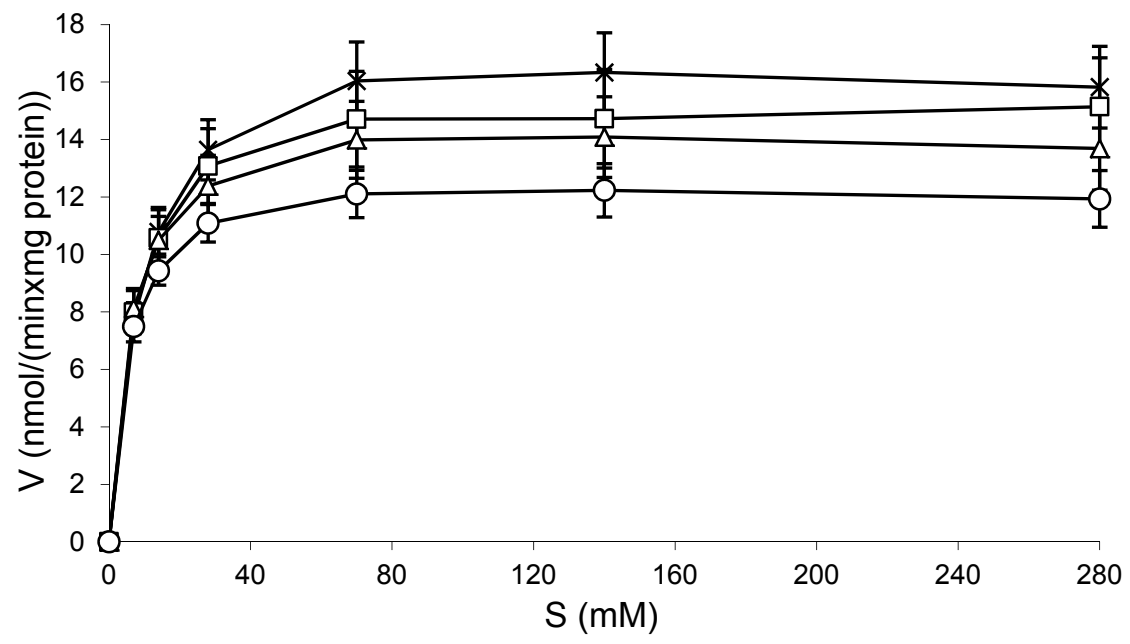

Figure 1. Michaelis-Menten curves for the substrate (sucrose) concentrations $0-280 \mathrm{mM}$ with and without L-arabinose as inhibitor of sucrase $(0.0 \mathrm{mM}(\mathrm{x}), 0.84 \mathrm{mM}(\square), 1.4 \mathrm{mM}(\Delta)$ and $2.8 \mathrm{mM}(\circ))$. Data are mean $\pm \operatorname{SEM}(n=6)$. $S$ is the substrate concentration and $V$ is the velocity of the reaction. (Reproduced from Krog-Mikkelsen et al (2) with permission). 
corresponding to $2.2 \mathrm{mg}$ protein/mL and disaccharide solutions at final concentrations of 7 , $14,28,140$, and $280 \mathrm{mM}$ in $0.1 \mathrm{M}$ maleate buffer, $\mathrm{pH}=6.0$ were used. The amount of glucose released by the enzymatic reaction was linear with time up to $60 \mathrm{~min}$, so a $30 \mathrm{~min}$ reaction time was used and glucose measured with a Cobas Mira Plus Spectrophotometer (Roche Diagnostic Systems, F Hoffmann-La Roche, Basel, Switzerland). Pentoses like L-arabinose and D-xylose were used as inhibitors at final concentrations of $0.84,1.4$, and $2.8 \mathrm{mM}$ as exemplified with Michaelis-Menten curves for L-arabinose in fig 1 and Lineweaver-Burk plots in fig 2 (9).

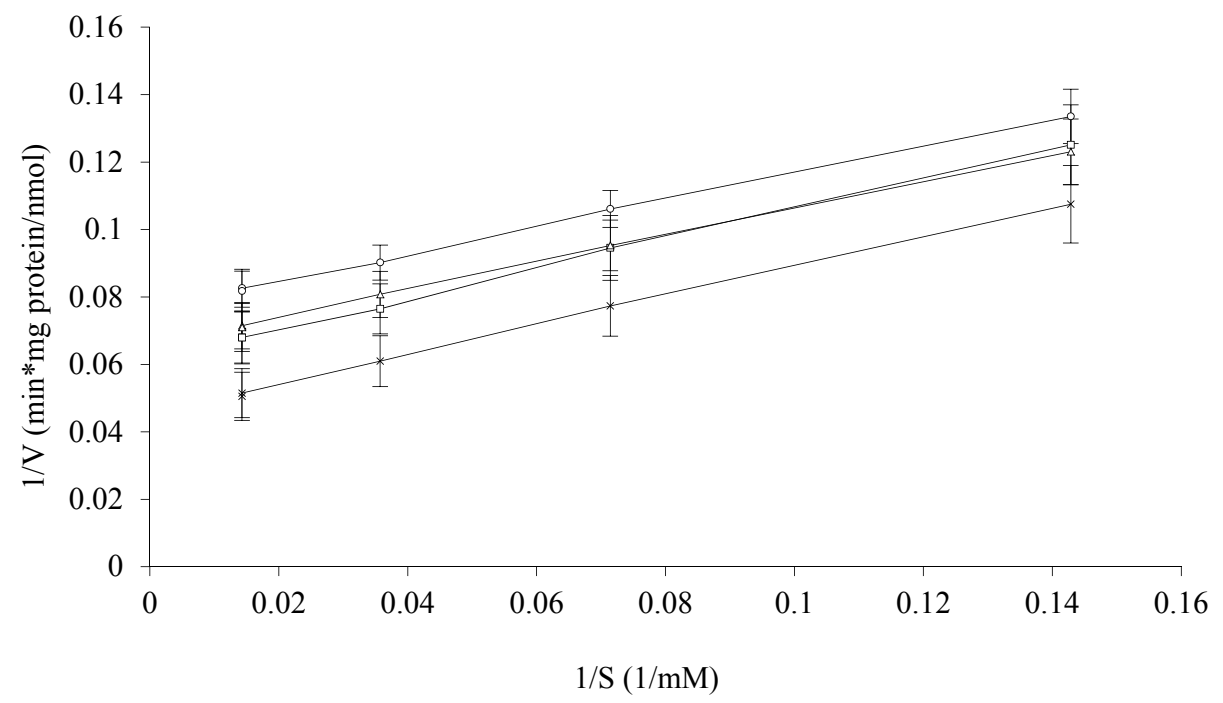

Figure 2. Lineweaver-Burk plots with and without L-arabinose as inhibitor of sucrase $(0.0 \mathrm{mM}(\mathrm{x})$, $0.84 \mathrm{mM}(\square), 1.4 \mathrm{mM}(\Delta)$ and $2.8 \mathrm{mM}(\circ)$ ). Data are mean \pm SEM $(\mathrm{n}=6)$. (Reproduced from Krog-Mikkelsen et al (2) with permission.)

Reaction velocity (v) plotted against substrate concentration (s) revealed classical MichaelisMenten kinetics and demonstrated significant inhibition by increasing amounts of L- 
arabinose (fig 1) Lineweaver-Burke analysis (fig 2) indicated uncompetitive inhibition since $\mathrm{V}_{\max }$ decreased from 19.8 over 14.7 and 14.1 to $12.2 \mathrm{nmol} /\left(\mathrm{min}^{*} \mathrm{mg}\right.$ protein), and $\mathrm{Km}$ decreased from 9.8 over 7.3 and 6.1 to $5.3 \mathrm{mmol} / \mathrm{L}$ when the inhibitor concentrations increased from zero over 0.84 and 1.4 to $2.8 \mathrm{mM} \mathrm{L}$-arabinose (data not shown). Thus, addition of $0.84,1.4$, and $2.8 \mathrm{mM}$ L-arabinose resulted in 25,29 and $38 \%$ inhibition of the sucrase activity, respectively at $V_{\max }$. The apparent $K_{i}$ was calculated to $2.8 \pm 0.3 \mathrm{mM}$ (mean \pm SEM, $n=3$ ) from the Lineweaver-Burke plots (2).

Similar results were obtained with sucrose as substrate and D-xylose as inhibitor, and with maltose as substrate and L-arabinose as inhibitor (data not shown).

The validity of the in vitro model was confirmed in a human intervention study with 15 healthy volunteers in a randomized double-blinded cross-over study. Sucrose beverages (75 $\mathrm{g}$ in $300 \mathrm{~mL}$ ) supplemented with $0,1,2$, or $3 \mathrm{~g}(0,1.3,2.7$ and $4 \mathrm{w} / \mathrm{w} \%$, respectively) Larabinose were tested (2). Blood was collected fasting and for 3-h postprandial with 15 minute intervals, and plasma glucose and serum insulin measured (fig 3 and 4).

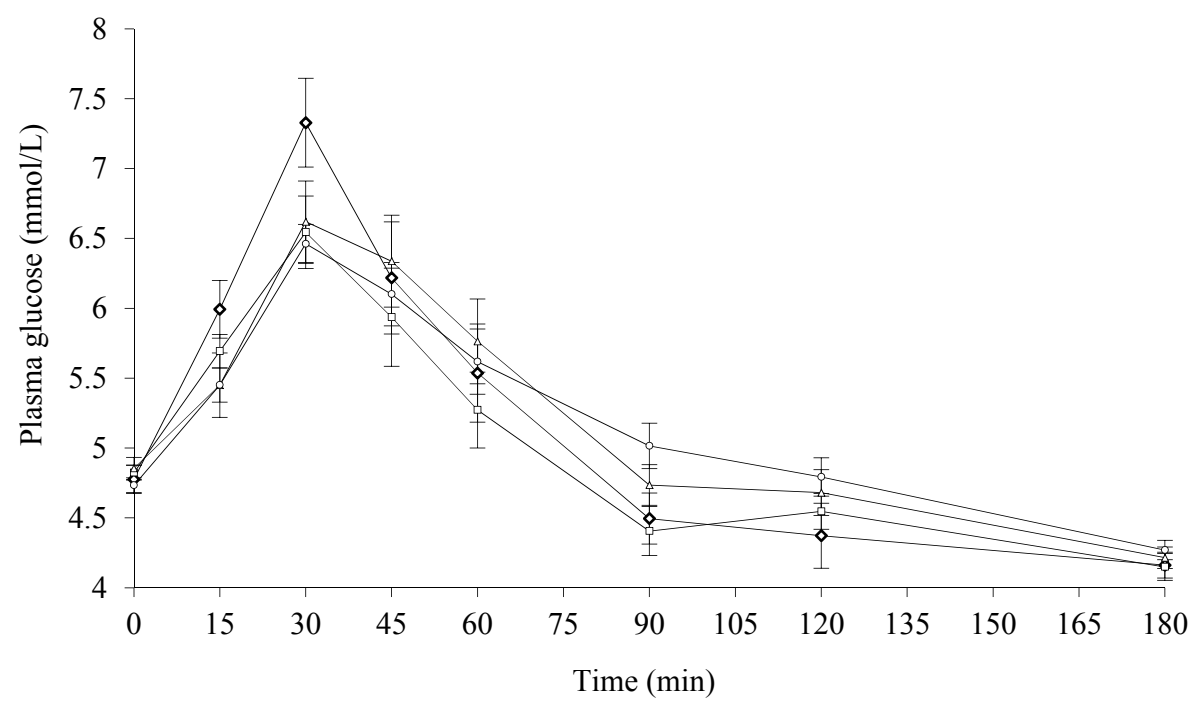

Figure 3. Plasma glucose in 15 normal male subjects after intake of sucrose drinks supplemented with $0(\mathrm{x}), 1(\square), 2(\Delta)$, or $3(\circ)$ grams of L-arabinose. Data are mean $( \pm$ SEM). iAUC $=$ incremental area under the curve. Statistical differences Peak, $\mathrm{P}=0.001$. Time to peak, $\mathrm{P}=0.133$. iAUC, $\mathrm{P}=0.245$. (Reproduced from Krog-Mikkelsen et al (9) with permission.) 
The present in vivo results in man strongly indicate that the Caco-2 cell model is useful in screening procedures in search for compounds which may lower the glycemic and insulimic responses in man. Importantly, because the Caco-2 cell line is of human origin, the results are more relevant for human physiology than studies with experimental animals.

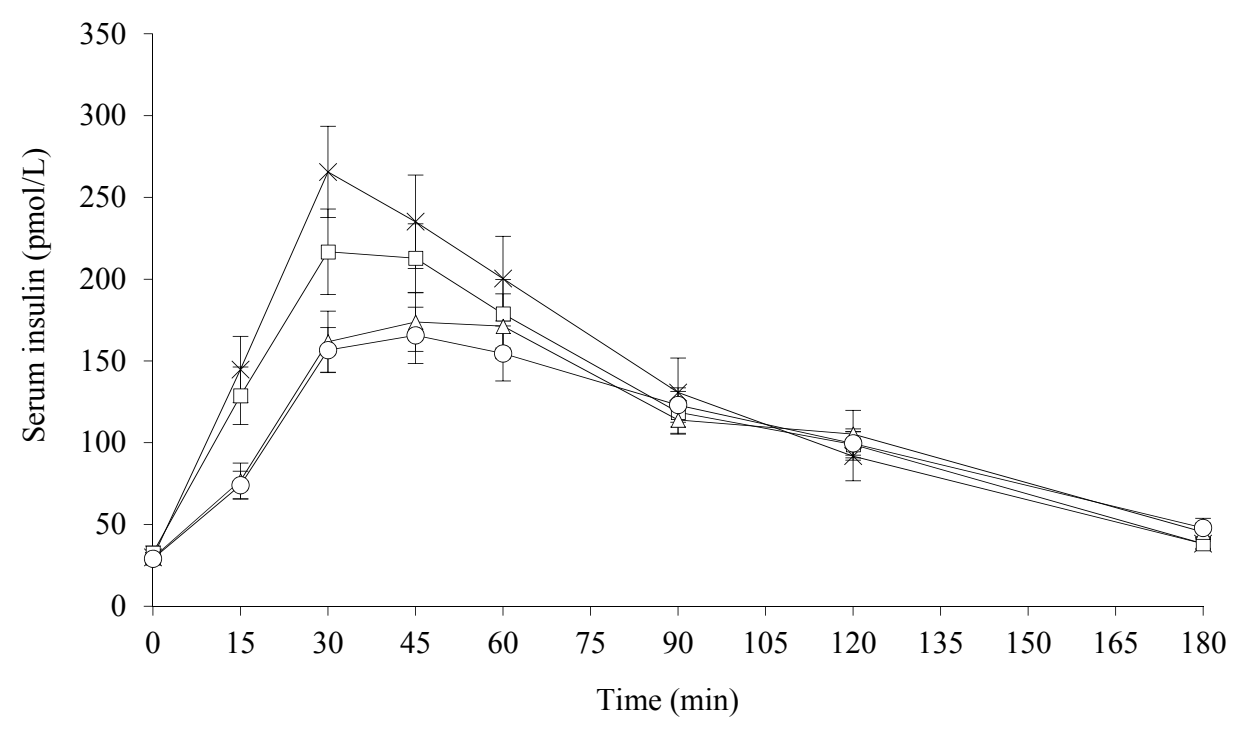

Figure 4. Serum insulin in 15 normal male subjects after intake of sucrose drinks supplemented with 0 $(x), 1(\square), 2(\Delta)$, or $3(\circ)$ grams of L-arabinose. Data are mean $( \pm$ SEM). Statistical differences Peak, $\mathrm{P}<0.0001$. Time to peak, $\mathrm{P}=0.002$. iAUC, $\mathrm{P}=0.017$. (Reproduced from Krog-Mikkelsen et al (9) with permission.)

\section{The inhibition of the uptake of maltose and sucrose by food components}

In addition to the pentoses L-arabinose and D-xylose growing evidence indicates that various dietary polyphenols may influence carbohydrate metabolism. Several efforts are 
made to identify new possible $\alpha$-glucosidase inhibitors and interest in replacement of synthetic foods by natural ones has fostered research on vegetable sources and screening of raw materials to identify these $\alpha$-glucosidase inhibitors (17-20). Polyphenols are abundant micronutrients in our diet, found in plants foods like fruits, vegetables, tea, coffee, red wine, and cacao. Studies with polyphenolic compounds, polyphenolic extracts of foods including berries, vegetables and colored grains such as black rice, green and black tea, and red wine have been shown to inhibit $\alpha$-glucosidase activities and there by suppress the elevation of blood glucose concentrations when tested in especially small rodents (18). Additionally, different cell lines like Caco 2 cells mentioned above have been used in vitro. The inhibitory polyphenols includes flavonoids, phenolic acids, tannins (18). For example gallic acid and tannic acid have showed to be potential inhibitors of sucrase and other brush border enzymes in mice and rat (15;21;22). Extracts of acerola fruit have been studied and shows reduced plasma glucose level after oral administration of maltose or sucrose in mice, indicating inhibition of $\alpha$-glucosidase effects on both sucrase and maltase in mice intestines (23-25). A hot water extract of leaves of Nerium Indicum, a bush from Pakistan, was found to reduce the rise in postprandial blood glucose when maltose and sucrose was given orally in rats. It was found that the extract inhibited $\alpha$-glycosidase, suggesting the isolated polyphenols from the leaves extract, chlorogenic acid, to be the inhibitor of maltase and sucrose (26).

\section{Sugar beets}

The nutritional value of sucrose is to provide calories; nevertheless some studies have found that in the process of refining sugar from sugar beets and sugar cane some of the by products like pulp and molasses are important sources of bioactive compounds (polyphenols and pentoses). A study with sugar beet pulp revealed that the pulp contained polyphenolic compounds and had antioxidant properties $(27 ; 28)$. The same has been shown in studies with sugar cane products (29). The sugar beet molasses contains a variety of different phenolic acids mostly vanillic acid, syringic acid, p-coumaric acid, gallic acid, protocatechuic acid and ferulic acid the most abundant.

For kinetic studies of sucrase activity, we used the aforementioned assay (2). As inhibitors two different polyphenol-rich fractions from chromatographic separation of molasses from sugar beets and pure ferulic acid were used. Results from the kinetic studies of EDC molasses, fraction III-2 molasses and pure ferulic acid (obtained from Nordic Sugar Denmark) are represented in figure 5-7.

There were no inhibitory effects of EDC molasses or fraction III-2. Ferulic acid showed a week inhibition of $1.9 \%$ for the concentration of $1 \mathrm{mM}$ (Unpublished data). The variability of polyphenol content in foods is pronounced and in most cases, foods contain complex mixtures of polyphenols. The content is influenced by numerous factors such as variety, production practices at a particular processing plant, environmental factors and by storage variables. Even though, molasses contain a variety of different phenolic acids and pure ferulic acid inhibition of sucrose activity was weak at a relatively low concentration. This 
indicates that there are still much to learn about the potential bioactivities and the bioavailabilities of polyphenolic compounds (30).

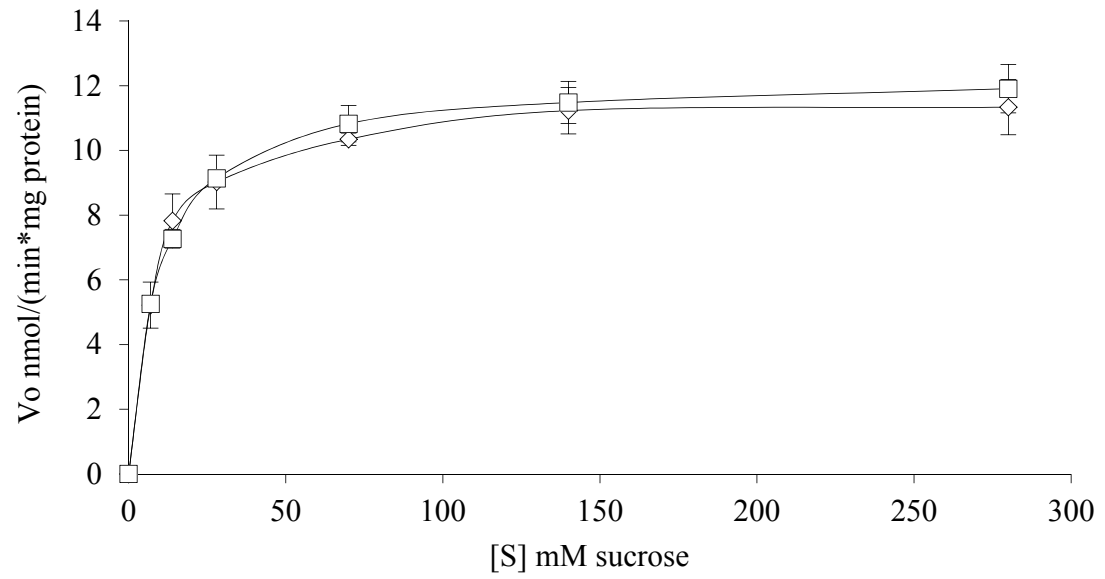

Figure 5. Michaelis-Menten curves for the substrate (sucrose) concentrations $0-280 \mathrm{mM}$ with and without fraction III-2 molasses as inhibitor of sucrose $(n=4)$. [sucrose $(\diamond)$ Fraktion III-2 molasses (口)]

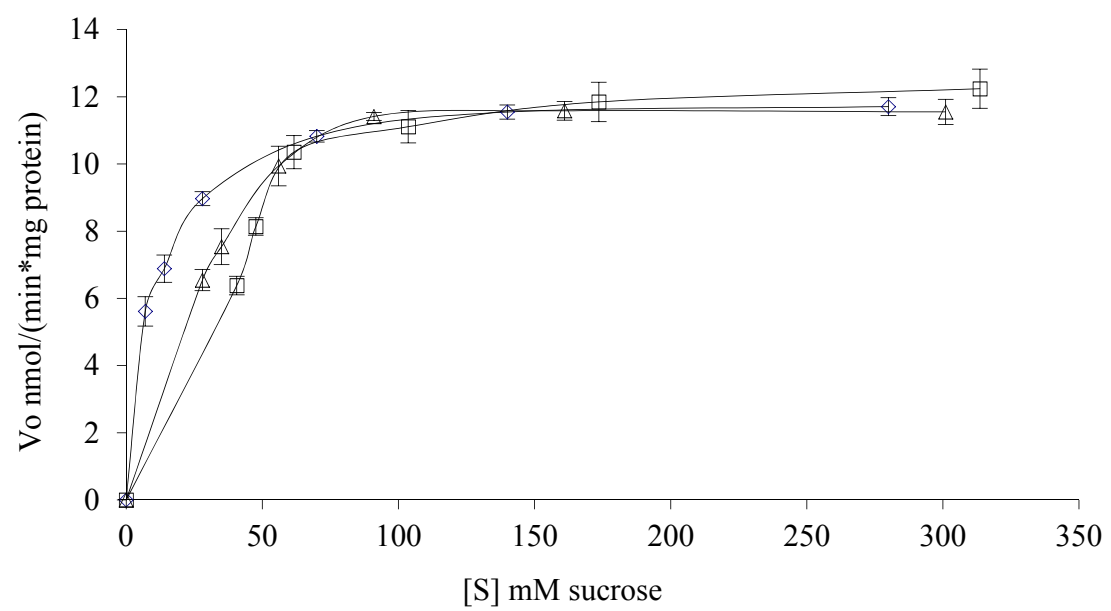

Figure 6. Michaelis-Menten curves for the substrate (sucrose) concentrations $0-280 \mathrm{mM}$ with and without $3 \%$ EDC molasses as inhibitor of sucrose $(n=4)$. Sucrose placebo represents the amount of sucrose in the EDC molasses.[sucrose ( $\diamond) 3 \%$ EDC molasses ( $\square$ ), Sucrose placebo $(\Delta)$ ] 


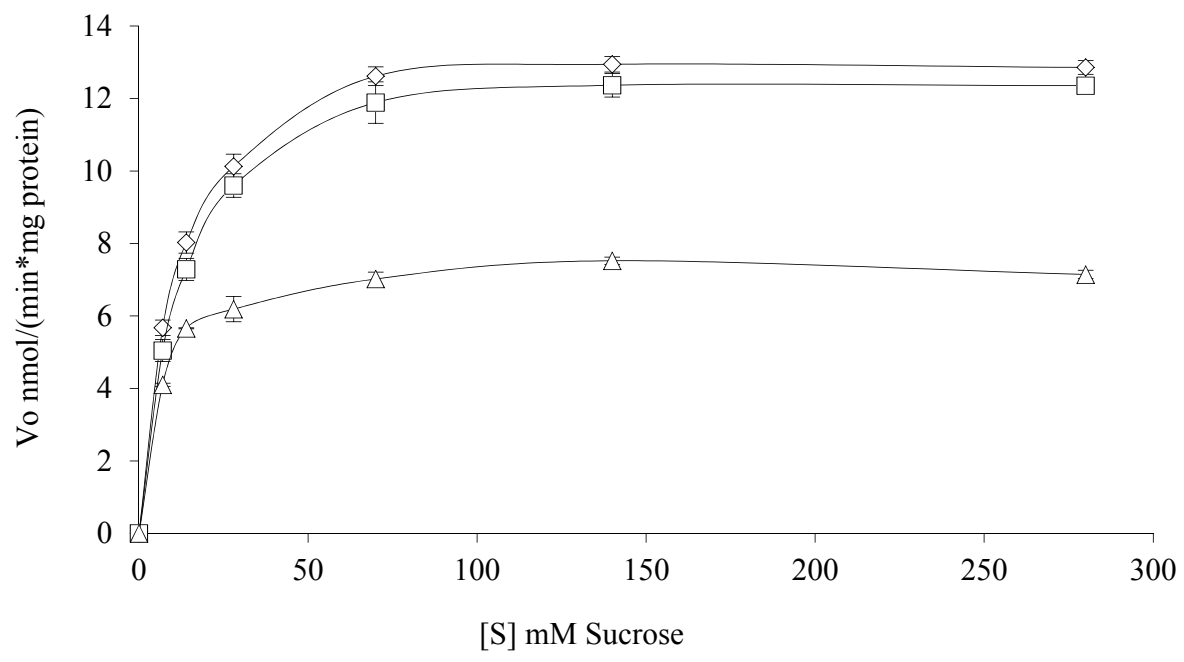

Figure 7. Michaelis-Menten curves for the substrate (sucrose) concentrations $0-280 \mathrm{mM}$ with and without $1 \mathrm{mM}$ ferulic acid as inhibitor of sucrase and 5,6 $\mathrm{mM}$ arabinose as inhibitor of sucrase. [sucrose $(\diamond) 1 \mathrm{mM}$ ferulic acid $(\square), 5,6 \mathrm{mM}$ arabinose $(\Delta)]$

\section{Intraluminal factors related to uptake of glucose}

It has been known for many years that dietary fibers reduce postprandial glucose concentrations in the blood, insulin response and delay gastric emptying. These effects have been established for a variety of fibers, but most markedly for soluble fibers. The character of chemical binding to the fibers are not well elucidated, neither the questions of existing physical binding mechanisms. The different processing methods of carbohydrates such as parboiling have verified effects on the glycemic response.

One could ask whether the fiber-effects are due to the fibers, or can be explained by compensatory effects on the diet. That means if intake of fibers in the relevant amounts decreases appetite for fat and short chain carbohydrates, and thereby induces early satiety or changes food preferences towards other kinds of nutrients. These questions have only been addressed in very few publications and deserve to be discussed further. It has been very difficult to show that changes by fibers on appetite and food intake last more than around three weeks. This could be due to adaptation both to the direct effect of fibers, but also to adaption to the secondary effects such as food composition. 
An additional question is the significance of formation of resistant starch during the preparation and production of food items.

During the 1980's it was well documented that dietary fibers have beneficial effects on blood glucose levels, the postprandial values in particular. The mechanisms, however, were not clear, and chemical bindings of glucose to elements in the fibers were hypothesized. Such bindings have never been convincingly proven, and at an early point these hypothesis were questioned. A study used pectin in the glucose solution and modulated gastric emptying with propantheline (31) which demonstrated that pectin significantly reduced bloodglucose, but propantheline had a more pronounced effect. In an additional investigation in the same paper they demonstrated that both gastric emptying and paracetamol absorption were slower after inclusion of gel fiber (guar gum and pectin), but the total absorption of the drug, reflected in urinary recovery, was not significantly reduced. These results indicated that gastric emptying could be the dominating factor in the delay of glucose absorption. Later a long list of authors has contributed. Lavin and Read (32) found no difference in gastric emptying time when comparing fluent meal of $30 \%$ glucose with or without guar gum, and speculated in an unknown mucosal receptor mechanism to explain the effects on postprandial blood glucose and insulin concentrations as well as satiety. In contradiction Horowitz et al (33) found convincing correlations between gastric emptying and peak plasma glucose as well as the total amount of glucose absorbed using a scintigraphic technique, but with almost twice the concentration of glucose in the fluent meal and a $40 \%$ larger volume compared to Lavin and Read (32). Horowitz et al (33) calculated that gastric emptying accounts for about $34 \%$ of the variance in postprandial peak plasma glucose. The difference between these results could be explained by the techniques used, but also by the concentrations of glucose in the test meals. A study investigated the rehydration ability of 2 and $10 \%$ glucose-electrolyte solutions with osmolality of 189 and $654 \mathrm{mOsm} / \mathrm{kg}$, respectively. Gastric volumes were determined via gastric aspiration at $15 \mathrm{~min}$ intervals. They showed that the reduced overall rate of fluid uptake following ingestion of the $10 \%$ glucose solution was due largely to a relatively slow rate of gastric emptying (34). Hence the influence of gastric emptying on glucose uptake may only be relevant for solutions with very high concentrations of glucose, which is not relevant in relation to the human diet neither in normal persons nor in diabetic patients. This is in accordance with the hypothesis, that gastric content is only allowed access to the duodenum when iso-osmotic. Part of the delay in gastric emptying may well to allow a dilution with secreted water and sodium.

All these results indicate that gastric emptying is probably the dominating factor, but not the only one. Blackburn et al (35) had the same results as others concerning the lowering of blood glucose and insulin, but there was no correlation between the changes in the individual blood glucose responses and changes in gastric emptying rates induced by guar. By a steady-state perfusion technique, glucose absorption was found to be significantly reduced during perfusion of the jejunum with solutions containing guar. They estimated the thickness of unstirred layer in addition, and concluded that guar improves glucose tolerance predominantly by reducing glucose absorption in the small intestine. These were very 
elegant experiments, but has not been reproduced. However, another important influence on glucose uptake may be the rate of perfusion of the small intestine which can be modulated both by hormonal effects and meal composition (36).

After glucose meals it seems like gastric emptying is a dominant intraluminal factor for glucose absorption. However, glucose is rarely ingested as glucose, and production of glucose in the stomach due to acid hydrolysis is not a predominant mechanism of glucose production. For these reasons it would be valuable to look at starch and sucrose as well.

the hypothesis was investigated In another study with focus on particle size and structural features of the food. An extract from barley was used to modify the granules and the particle size, and found a decrease in the in-vitro starch digestion and accordingly release of glucose (37). Also starch-entrapped microspheres have been used with similar beneficial effects on the postprandial blood glucose response for different starch fractions (38). In addition it would be relevant to investigate the effects on brush border sucrose activity related to the different forms of glucose suppliers.

In animal studies promising results are emerging. Kett et al (39) found that starch gelatinized with $\alpha$-casein resulted in lower postprandial glucose uptake than starch gelatinized with $\beta$-casein. In rats a study found indications of an effect of addition of resistant starch to bread, but different effects for maize and wheat based bread (40).

Besides from the more or less well described factors mentioned above, we see an emerging and probably very important field of intestinal sensing of nutrients, recently reviewed by Tolhurst et al (41). Of special interest in the glucose aspect are the documented effects of psyllium fibers in the diet prolonging pancreatic polypeptide (PYY) secretion and suppressing postprandial glucagon-like peptide-1(GLP-1) concentration (42).

\section{Conclusions}

All together, these findings imply that there must be many possible ways of modifying food components to reduce the postprandial glucose levels in the blood. These modifications can be made both by induction of physical changes in the carbohydrates (gelatinization), additives and addition of food components already existing in nature. Arabinose is present in considerable amounts in the sugar beet along with sucrose, but the components are separated during the manufacturing process. Modifications of food components generally cost money, so it will partly be the consciousness of the consumers that will determine whether such products have a future on the market.

The simplest way of getting an effect is still to increase the amount of dietary fibers in the diet, and hypothetically the largest effects would result from a change in eating habits in the total population. The results presented are from normal volunteers, and the same effects can be measured in diabetics, whereas results are lacking from persons/patients with insulin resistance but not yet diabetic. 


\section{Author details}

Kia Halschou Hansen and Klaus Bukhave

Department of Human Nutrition, University of Copenhagen, Denmark

Jens Rikardt Andersen*

Department of Human Nutrition, University of Copenhagen, Denmark

Nutrition Unit 5711, Rigshospitalet, Copenhagen, Denmark

\section{Conflicts of interest}

Kia Halschou Hansen, MSc in clinical nutrition, is a $\mathrm{PhD}$ candidate, partly financed by Nordic Sugar Denmark.

\section{References}

[1] Gin H, Rigalleau V. Post-prandial hyperglycemia. post-prandial hyperglycemia and diabetes. Diabetes Metab 2000;26:265-72.

[2] Haffner SM, Stern MP, Hazuda HP, Mitchell BD, Patterson JK. Cardiovascular risk factors in confirmed prediabetic individuals. Does the clock for coronary heart disease start ticking before the onset of clinical diabetes? JAMA 1990;263:2893-8.

[3] Lindstrom J, Ilanne-Parikka P, Peltonen $\mathrm{M}$ et al. Sustained reduction in the incidence of type 2 diabetes by lifestyle intervention: follow-up of the Finnish Diabetes Prevention Study. Lancet 2006;368:1673-9.

[4] Knowler WC, Hamman RF, Edelstein SL et al. Prevention of type 2 diabetes with troglitazone in the Diabetes Prevention Program. Diabetes 2005;54:1150-6.

[5] Knowler WC, Barrett-Connor E, Fowler SE et al. Reduction in the incidence of type 2 diabetes with lifestyle intervention or metformin. N Engl J Med 2002;346:393-403.

[6] Gerstein HC, Yusuf S, Bosch J et al. Effect of rosiglitazone on the frequency of diabetes in patients with impaired glucose tolerance or impaired fasting glucose: a randomised controlled trial. Lancet 2006;368:1096-105.

[7] Pan XR, Li GW, Hu YH et al. Effects of diet and exercise in preventing NIDDM in people with impaired glucose tolerance. The Da Qing IGT and Diabetes Study. Diabetes Care 1997;20:537-44.

[8] Tuomilehto J, Lindstrom J, Eriksson JG et al. Prevention of type 2 diabetes mellitus by changes in lifestyle among subjects with impaired glucose tolerance. N Engl J Med 2001;344:1343-50.

[9] Krog-Mikkelsen I, Hels O, Tetens I, Holst JJ, Andersen JR, Bukhave K. The effects of 1arabinose on intestinal sucrase activity: dose-response studies in vitro and in humans. The American Journal of Clinical Nutrition 2011;94:472-8.

\footnotetext{
${ }^{*}$ Corresponding Author
} 
[10] Elliott SS, Keim NL, Stern JS, Teff K, Havel PJ. Fructose, weight gain, and the insulin resistance syndrome. Am J Clin Nutr 2002;76:911-22.

[11] Sievenpiper JL, Carleton AJ, Chatha S et al. Heterogeneous effects of fructose on blood lipids in individuals with type 2 diabetes: systematic review and meta-analysis of experimental trials in humans. Diabetes Care 2009;32:1930-7.

[12] Sievenpiper JL, Chiavaroli L, de Souza RJ et al. 'Catalytic' doses of fructose may benefit glycaemic control without harming cardiometabolic risk factors: a small meta-analysis of randomised controlled feeding trials. Br J Nutr 2012;108:418-23.

[13] Seri K, Sanai K, Matsuo N, Kawakubo K, Xue C, Inoue S. L-arabinose selectively inhibits intestinal sucrase in an uncompetitive manner and suppresses glycemic response after sucrose ingestion in animals. Metabolism 1996;45:1368-74.

[14] Semenza G, von Balthazar AK. Steady-state kinetics of rabbit-intestinal sucrase. Kinetic mechanism, Na+ activation, inhibition by tris(hydroxymethyl)aminomethane at the glucose subsite. Eur J Biochem 1974;41:149-62.

[15] Welsch CA, Lachance PA, Wasserman BP. Effects of native and oxidized phenolic compounds on sucrase activity in rat brush border membrane vesicles. J Nutr 1989;119:1737-40.

[16] Delie F, Rubas W. A human colonic cell line sharing similarities with enterocytes as a model to examine oral absorption: advantages and limitations of the Caco-2 model. Crit Rev Ther Drug Carrier Syst 1997;14:221-86.

[17] Keen CL, Holt RR, Oteiza PI, Fraga CG, Schmitz HH. Cocoa antioxidants and cardiovascular health. Am J Clin Nutr 2005;81(suppl):298-303.

[18] Hanhineva K, Torronen R, Bondia-Pons I et al. Impact of Dietary Polyphenols on Carbohydrate Metabolism. Int J Mol Sci 2010;11:1365-402.

[19] Sies H, Schewe T, Heiss C, Kelm M. Cocoa polyphenols and inflammatory mediators. Am J Clin Nutr 2005;81(suppl):304-12.

[20] Vita JA. Polyphenols and cardiovascular disease: effects on endothelial and platelet function. Am J Clin Nutr 2005;81(suppl):292-7.

[21] Gupta S, Mahmood S, Khan RH, Mahmood A. Inhibition of brush border sucrase by polyphenols in mouse intestine. Biosci Rep 2010;30:111-7.

[22] Navita G, Shiffalli G, Akhtar MN. Gallic acid inhibits brush border disaccharidases in mammalian intestine. Nutrition Research 2007;27:230-5.

[23] Ani V, Varadaraj MC, Naidu KA. Antioxidant and antibacterial activities of polyphenolic compounds from bitter cumin (Cuminum nigrum L.). Eur Food Res Techn 2006;224:109-15.

[24] Hanamura T, Mayama C, Aoki H, Hirayama Y, Shimizu M. Antihyperglycemic effect of polyphenols from Acerola (Malpighia emarginata DC.) fruit. Biosci Biotechnol Biochem 2006;70:1813-20.

[25] Matsui T, Ogunwande IA, Abesundara KJ, Matsumoto K. Anti-hyperglycemic Potential of Natural Products. Mini Rev Med Chem 2006;6:349-56. 
[26] Ishikawa A, Yamashita $\mathrm{H}$, Hiemori $\mathrm{M}$ et al. Characterization of inhibitors of postprandial hyperglycemia from the leaves of Nerium indicum. J Nutr Sci Vitaminol 2007;53:166-73.

[27] Mohdaly AA, Sarhan MA, Smetanska I, Mahmoud A. Antioxidant properties of various solvent extracts of potato peel, sugar beet pulp and sesame cake. J Sci Food Agric 2010;90:218-26.

[28] Sakac MB, Gyura JF, Misan AC, Seres ZI. Antioxidant properties of sugarbeet fibers. Zuckerindustrie 2009;134:418-25.

[29] Ranilla LG, Kwon YI, Genovese MI, Lajolo FM, Shetty K. Antidiabetes and antihypertension potential of commonly consumed carbohydrate sweeteners using in vitro models. J Med Food 2008;11:337-48.

[30] Manach C, Scalbert A, Morand C, Remesy C, Jimenez L. Polyphenols: food sources and bioavailability. Am J Clin Nutr 2004;79:727-47.

[31] Holt S, Heading RC, Carter DC, Prescott LF, Tothill P. Effect of gel fibre on gastric emptying and absorption of glucose and paracetamol. Lancet 1979;1:636-9.

[32] Lavin JH, Read NW. The effect on hunger and satiety of slowing the absorption of glucose: relationship with gastric emptying and postprandial blood glucose and insulin responses. Appetite 1995;25:89-96.

[33] Horowitz M, Edelbroek MA, Wishart JM, Straathof JW. Relationship between oral glucose tolerance and gastric emptying in normal healthy subjects. Diabetologia 1993;36:857-62.

[34] Evans GH, Shirreffs SM, Maughan RJ. The effects of repeated ingestion of high and low glucose-electrolyte solutions on gastric emptying and blood $2 \mathrm{H} 2 \mathrm{O}$ concentration after an overnight fast. Br J Nutr 2011;106:1732-9.

[35] Blackburn NA, Redfern JS, Jarjis $\mathrm{H}$ et al. The mechanism of action of guar gum in improving glucose tolerance in man. Clin Sci 1984;66:329-36.

[36] Macdonald IA. Physiological regulation of gastric emptying and glucose absorption. Diabet Med 1996;13:11-5.

[37] Razzaq HA, Sutton KH, Motoi L. Modifying glucose release from high carbohydrate foods with natural polymers extracted from cereals. J Sci Food Agric 2011;91:2621-7.

[38] Venkatachalam M, Kushnick MR, Zhang G, Hamaker BR. Starch-entrapped biopolymer microspheres as a novel approach to vary blood glucose profiles. J Am Coll Nutr 2009;28:583-90.

[39] Kett AP, Bruen CM, O'Halloran F et al. The effect of alpha- or beta-casein addition to waxy maize starch on postprandial levels of glucose, insulin, and incretin hormones in pigs as a model for humans. Food Nutr Res 2012;56.

[40] Brites CM, Trigo MJ, Carrapico B, Alvina M, Bessa RJ. Maize and resistant starch enriched breads reduce postprandial glycemic responses in rats. Nutr Res 2011;31:302-8.

[41] Tolhurst G, Reimann F, Gribble FM. Intestinal sensing of nutrients. Handb Exp Pharmacol 2012;309-35. 
[42] Karhunen LJ, Juvonen KR, Flander SM et al. A psyllium fiber-enriched meal strongly attenuates postprandial gastrointestinal peptide release in healthy young adults. J Nutr 2010;140:737-44. 